\title{
Reflexões sobre a participação de um aprendiz em uma Comunidade de Prática
}

\section{Reflections about an apprentice participation in a Community of Practice}

Marcos Cesar Polifemi é doutor em Linguística Aplicada e Estudos da Linguagem (LAEL/PUC-SP) e, atualmente, atua como Gerente de Projetos Especiais da Cultura Inglesa São Paulo.

Contato: mcpolifemi@gmail.com

\section{Resumo}

Neste artigo, após discutir brevemente o conceito de comunidades e refletir, especificamente, sobre alguns dos elementos comuns a diferentes tipos de comunidade, analisarei a iniciação de um participante novato em uma Comunidade de Prática, sob a perspectiva de sua participação periférica legítima (LAVE; WENGER, 1991). Este estudo de caso (NUNAN, 1992), conduzido a partir da análise das interações ocorridas em um curso a distância de formação continuada para coordenadores, permitiu observar a ocorrência de estratégias discursivas que indicam a importância de se assumir, declaradamente, uma postura de aprendiz como forma de obter uma melhor acolhida do restante do grupo e, com isso, construir um contexto apropriado para que a colaboração e a aprendizagem possam ocorrer.

Palavras-chave: Comunidade de Prática; aprendizagem; participação periférica legítima; educação à distância.

\section{Abstract}

In this article, after a discussion about the concept of communities and a reflection about some of the elements that are common to different types of communities, I will analyze the initiation process of a novice participant in a Community of Practice under the perspective of his peripheral legitimate 
participation (LAVE; WENGER, 1990). The case study (NUNAN, 1992) was conducted through the analysis of the interactions sustained in an online continuing education course aimed at academic coordinators. It revealed the emergence of discourse strategies that emphasize the importance of one assuming an explicit apprentice attitude as a way to be accepted in an ongoing teacher education study group and, by doing so, helping in the constitution of an appropriate context for collaboration and learning to occur.

Keywords: Community of practice; learning; legitimate peripheral participation; distance education.

\section{Introdução}

Estudos sobre comunidades têm sido conduzidos por diversos pesquisadores como Lave e Wenger (1991), Garrison, Anderson e Archer (2000), Wenger (1998), Jonassen, Peck e Wilson (1999) e Cicognani (1998), e têm abrangido diferentes áreas do conhecimento, como as Ciências Sociais, a Educação, a Linguística, as Ciências da Informação, entre outras.

A origem de alguns desses estudos, no entanto, se deu a partir da obra de Tönnies (1957), o qual buscou uma definição para o conceito de comunidades a partir de sua comparação com a sociedade. Segundo Tönnies (1957), de uma forma geral, as comunidades se distinguem das sociedades em função de serem menos abrangentes, por se constituírem a partir de interesses comuns que se estabelecem em função de um "desejo natural" em um tempo passado, e de apresentarem uma dinâmica orgânica de autorregulação e cooperação. Já as sociedades se caracterizam preponderantemente por ambições individuais e atitudes competitivas, por interesses materiais e de ordem econômica (menos comuns nas comunidades), que se manifestam em função de um desejo racional, mais direcionado para o futuro.

As características mencionadas acima podem nos levar a assumir que todo agrupamento auto-organizado de pessoas com interesses em comum e que trabalham cooperativamente se constitui em uma comunidade. Porém, a partir desses elementos, outros ingredientes têm sido adicionados ao conceito de comunidade, o que tem dado margem à criação de alguns tipos específicos de comunidades, entre elas as de Prática, as de Aprendizagem, as Discursivas, as de Questionamento e as Virtuais, 
que embora possam parecer, a princípio, muito diferentes entre si, apresentam vários aspectos em comum.

Um desses aspectos em comum é a aprendizagem, a qual pretendo abordar neste estudo por meio da discussão sobre a forma como se propõe sua inserção nas Comunidades de Questionamento, de Aprendizagem, e de Prática. Em um segundo momento, ela será explorada sob a perspectiva da participação de um aluno novato em uma comunidade já estabelecida.

\section{A aprendizagem nas comunidades}

\subsection{A aprendizagem na Comunidade de Questionamento}

A aprendizagem é um dos elementos constitutivos do modelo de Comunidade de Questionamento proposto por Garrison, Anderson e Archer (2000). Segundo esses autores, a aprendizagem ocorre nesse tipo de comunidade pela interação de três elementos centrais: o cognitivo, o social e o de ensino.

0 elemento cognitivo relaciona-se às possibilidades que os membros da comunidade têm de construir sentido, por meio da comunicação sustentada. 0 elemento social diz respeito à habilidade que os participantes possuem de imprimir ao grupo suas características pessoais de forma a fortalecer as bases de relacionamentos interpessoais, facilitando assim que o aspecto cognitivo ocorra. Já o elemento de ensino consiste em duas funções básicas. A primeira é a do desenho da experiência educacional, o que inclui a previsão de tarefas, discussões e resultados, sem contar a avaliação da experiência. A segunda função é a de facilitador do processo, tarefa esta que, segundo os autores, pode ser executada por qualquer um dos participantes da comunidade. 0 elemento de ensino (desenho e facilitação) funciona como o meio pelo qual a comunidade dá suporte e maximiza os outros dois elementos: o social e o cognitivo.

Para Garrison, Anderson e Archer (2000), a interação desses três elementos se constitui em uma experiência educacional e, nesse sentido, ao se embasarem na obra do filósofo John Dewey, dão ênfase a outro aspecto importante para qualquer dos três elementos desse modelo de comunidade de questionamento: "o trabalho colaborativo de reconstrução da experiência" (p. 92).

Essa visão também reforça a importância que os autores imputam à negociação de sentidos. Ou seja, em uma experiência 
educacional, para se construir sentido pela interação, os participantes precisam se engajar em um processo colaborativo de negociação de sentidos que se dá de forma mais tranquila se houver, por parte dos participantes, espaço para que eles possam, por meio dos três elementos - cognitivo, social e de ensino -, atuar não tendo que se anular como participantes.

Em outras palavras, isso se equivaleria a afirmar que, tendo um mesmo objetivo e ao se conhecerem melhor, os participantes da Comunidade de Questionamento teriam mais conhecimentos em comum, isto é, mais base para compartilhar suas experiências de vida e, nesse processo, construir novas experiências a partir de atividades desenhadas e facilitadas pelo professor, como defendem os autores: "argumentamos que a presença cognitiva é mais facilmente sustentada após uma significativa parcela de presença social ter sido estabelecida" (GARRISON; ANDERSON; ARCHER, 2000, p. 95, tradução nossa).

A única ressalva que se faz a esse modelo de Comunidade de Questionamento relaciona-se ao elemento de ensino. Se por um lado os autores (op. cit.) afirmam que esse elemento, ou parte dele pelo menos, pode ser exercido não só pelo professor, mas por qualquer um dos participantes, por outro, ao discutirem o papel do professor, colocam nele toda a responsabilidade pelo processo, quase que negando a corresponsabilidade dos outros membros da comunidade:

\footnotetext{
Por meio de uma intervenção efetiva, o professor atrai os participantes menos ativos para a discussão, reconhece contribuições individuais, reforça contribuições apropriadas, enfoca as discussões mais importantes e, de forma geral, facilita a transação educacional. (GARRISON; ANDERSON; ARCHER, 2000, p. 101, tradução nossa).
}

Toda esta ênfase no que o professor deve fazer, mencionada na citação acima, atinge seu ponto máximo quando na sequência de sua obra os autores afirmam que a mais importante das responsabilidades no elemento do ensino é a "instrução direta". Com isso, não quero negar que muitas dessas responsabilidades sejam dos professores, mas creio que em um modelo no qual a colaboração é tida como fundamental, poderia haver uma maior distribuição do comando ou, se preferirem, do poder, que, de acordo com minha interpretação, fica muito nas mãos do professor. 


\subsection{A aprendizagem e sua própria comunidade}

Para Downes (2004), discutir a aprendizagem em comunidades chega quase a ser uma redundância. Para ele, os conceitos de aprendizagem e de comunidade são quase inseparáveis, mesmo se considerarmos alunos autodidatas.

Essa ideia de inseparabilidade parece ficar ainda mais evidente ao considerarmos as Comunidades de Aprendizagem propriamente ditas. Jonassen, Peck e Wilson (1999), ressaltam, no entanto, que nem todas as escolas ou cursos podem ser caracterizados como Comunidades de Aprendizagem. Eles ainda afirmam que, para que isso venha a ocorrer, seria necessário que houvesse no grupo pessoas que compartilhassem conhecimentos, valores e objetivos, o que nem sempre pode ser encontrado em cursos ou escolas. Segundo os autores:

\footnotetext{
Dentro das salas de aula há comunidades ou pequenos grupos sociais, porém seu objetivo não é o de aprender junto ou uns com os outros. Ao invés disso, esses pequenos grupos procuram reforçar socialmente suas próprias identidades pela exclusão de outrem. Comunidades de Aprendizagem emergem quando os alunos compartilham interesses comuns (p. 118, tradução nossa).
}

Dessa forma, não podemos restringir as Comunidades de Aprendizagem ao ambiente escolar. Gordin e colaboradores (1996) afirmam que esse é apenas um dos tipos de Comunidade de Aprendizagem. Um segundo tipo é aquele baseado em contextos profissionais (ou de trabalho).

As comunidades baseadas em contextos escolares são aquelas nas quais aprendizes e professores se envolvem em projetos colaborativos possibilitando que, no processo de se trabalhar em conjunto para um objetivo comum, os participantes aprendam uns com os outros.

Já nas comunidades baseadas em ambientes profissionais, os participantes aprendem as práticas de uma profissão ou disciplina por meio dos exemplos e da convivência na própria comunidade. Nesse tipo de comunidade, há a intersecção do conceito de Comunidade de Aprendizagem com o conceito de Comunidade de Prática, ou seja, a partir da definição de Gordin e colaboradores (1996), podemos inferir que uma Comunidade de Aprendizagem de base profissional se constitui em uma Comunidade de Prática, como definida por Wenger (1998, p. 45, tradução nossa): 


\begin{abstract}
Estar vivo na condição de ser humano implica em estar constantemente engajado na superação de desafios de todos os tipos [...] Na medida em que definimos esses desafios e, em um grupo, nos engajamos na sua consecução, interagimos uns com os outros e com o contexto e, nesse processo, modulamos nossas relações com cada uma dessas partes. Em outras palavras, nós aprendemos uns com os outros e aprendemos com e através de nossa relação com o mundo. Com o tempo, esse aprendizado coletivo resulta em práticas sociais que refletem tanto as buscas de nossos desafios, quanto as relações sociais inerentes ao seu processo de consecução. Essas práticas se tornam, por esse motivo, propriedade de uma comunidade criada ao longo de um tempo por meio da busca sustentada de objetivos compartilhados. Faz sentido, portanto, chamá-las de comunidades de prática.
\end{abstract}

Além desse ponto de intersecção, no qual uma Comunidade de Aprendizagem se transforma em uma Comunidade de Prática, é interessante também perceber que ao se pensar a aprendizagem em comunidades, novamente a colaboração e uma atitude ativa de todos os participantes em relação à sua aprendizagem emergem como fundamentais para que haja a construção de significados, sejam esses mais relacionados às práticas escolares, ou à atividade profissional, o que novamente nos remete ao trabalho de Wenger e Lave (1991), no qual discutem a aprendizagem situada, tema a ser abordado na sequência deste artigo.

\title{
1.3 A aprendizagem nas Comunidades de Prática
}

Entender a aprendizagem como sendo colaborativamente construída em comunidades significa trabalhar educacionalmente para que a escola tenha, dê possibilidades e oportunize a participação ativa de seus participantes na constituição dessas comunidades.

Como mencionado anteriormente, para Lave e Wenger (1991), as práticas sociais em comunidades se constituem a partir dos resultados coletivos de aprendizagem que emergem tanto de buscas pessoais quanto das relações sociais nas quais nos engajamos. Para podermos nos envolver nessas buscas, precisamos iniciar nossa participação nessas comunidades de forma periférica (em contraposição à participação integral dos membros mais antigos). Em outras palavras, ao nos iniciarmos em uma Comunidade de Prática, temos uma participação menos abrangente (ou menos integral). No entanto, essa participação é legítima e centrada no processo de aprendizagem, de forma que cada vez mais possa se mover em direção da integralidade, como em um movimento centrípeto. 
Ao discutir esse movimento nas Comunidades de Prática, entendendo a aprendizagem pelo viés da participação periférica legítima, os autores, cujo embasamento está ancorado declaradamente no socioconstrutivismo vygotskiano, argumentam que para que a aprendizagem situada ocorra, há a necessidade de termos um currículo orientado não para o ensino, mas sim para a aprendizagem. De acordo com Lave e Wenger (1991):

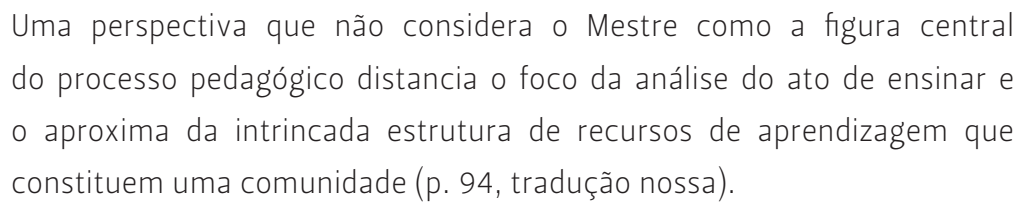

Esse descentramento mencionado pelos autores ocasiona também outros movimentos na comunidade que parecem ter impacto no papel do professor, do aluno e do conhecimento. Em uma leitura preliminar da obra de Vygotsky (1934/1984), a aprendizagem se dá pela e na interação do aprendiz com um par mais desenvolvido, que o ajuda com as tarefas que sozinho ainda não dá conta. Nesse sentido, coloca importante parte do processo nesse "par mais desenvolvido". Seria ele quem, tendo o saber daquele aspecto específico, interagiria com o aprendiz, identificando e possibilitando sua ação na "Zona Proximal de Desenvolvimento" (ZPD) e, com isso, a construção do conhecimento.

Para Lave e Wenger (1991), em uma Comunidade de Prática, essa relação com o par mais desenvolvido também pode ser observada na relação entre mestre e aprendiz. Nesse caso, o papel do "par mais desenvolvido" em uma determinada tarefa é o de possibilitar o acesso do aprendiz ao conhecimento constituído na e constituinte da comunidade. Ou seja, tanto para Vygotsky quanto para Lave e Wenger, o foco está na interação como ferramenta para se ter acesso às práticas sociais que constroem o conhecimento das quais tanto o aprendiz quanto o mestre são partes ativas.

Assim, a aprendizagem situada (produzida como resultado de um processo de negociação de sentidos sócio-históricoculturais) se constituiria a partir de uma base já construída que o aluno traz consigo. Com essa base, o aluno começa a interagir com o conhecimento de uma dada comunidade de prática, acessando esse conhecimento por meio de sua participação periférica legítima, na relação com membros, cuja participação na comunidade é mais integral. 
Essa base com a qual o aprendiz inicia sua participação na Comunidade de Prática é desconhecida do professor e pode muitas vezes trazer inovações para as práticas do grupo. Dessa forma, por meio da participação dos seus membros mais iniciantes, a comunidade se mantém e se revigora, legitimando tanto a participação de um novato, quanto a possibilidade de o mestre aprender com esse aprendiz.

\section{Enquanto isso, nas comunidades virtuais...}

Tendo discutido a forma como a aprendizagem é encarada nas Comunidades de Questionamento, de Aprendizagem e de Prática, nesta parte do trabalho buscarei nas Comunidades Virtuais a ligação, ou link, entre a fundamentação teórica do trabalho e o seu lado aplicado, estudado pela análise da participação periférica legítima de um aluno novato em uma Comunidade Virtual de Prática.

Um dos aspectos que há algum tempo tinha importância considerável no delineamento de comunidades relacionava-se ao espaço geográfico em comum onde as comunidades podiam estabelecer suas bases ou sedes. No entanto, com a proliferação da internet e, principalmente, das Tecnologias de Interação e Comunicação (TICs), o aspecto geográfico perdeu importância em alguns casos, ou melhor, oportunizou que pessoas que antes, por uma questão de distanciamento físico, dificilmente se encontrariam, possam por meio das TICs se engajar em práticas colaborativas das mais diversas e constituírem, assim, Comunidades Virtuais.

Para Rheingold (1993), Comunidades Virtuais emergem de uma surpreendente intersecção entre a humanidade e a tecnologia:

\footnotetext{
Como aprendemos com a história do telefone, do rádio e da televisão, as pessoas podem adotar novos meios de comunicação e redesenhar sua utilização e sua razão de existir com velocidade surpreendente. Computadores, modems e redes de comunicação povoam a infraestrutura tecnológica das redes de comunicação mediadas por computador (RCMC); o ciberespaço é o locus conceitual no qual palavras e relações humanas, dados, riqueza e poder se manifestam por meio de pessoas usuárias da tecnologia da RCMC (p. 58, tradução nossa).
}

Essa intersecção entre a humanidade e tecnologia concretiza-se pela linguagem que, no caso das Comunidades Virtuais, se dá na maioria das vezes por escrito, seja por trocas de mensagens, ou de 
participações em fóruns, listas de discussão e chats, entre outras possibilidades.

Cicognani (1998) vai inclusive além. A autora argumenta que o ciberespaço é constituído pela linguagem. Tudo que existe na internet, segundo ela, é linguagem. Desde os programas que usamos para navegação (e a própria navegação, inclusive), até os hyperlinks que utilizamos, passando pelo conteúdo que acessamos e bancos de dados através dos quais navegamos, todos são constituídos por algum tipo de linguagem. De acordo com essa autora,

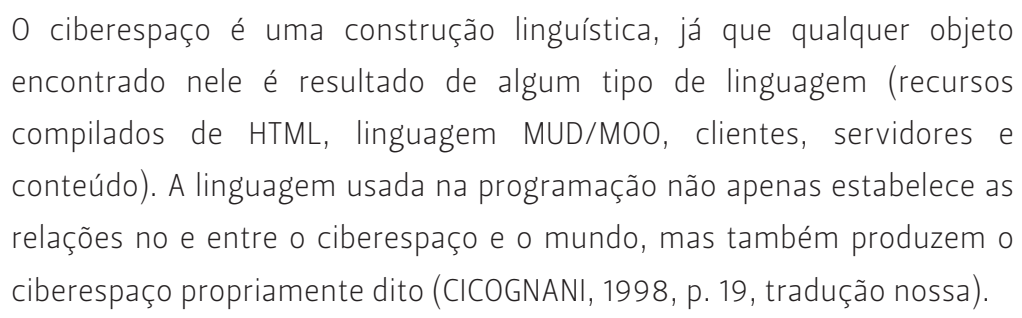

Ainda sobre esse tópico, a autora afirma haver dois tipos de uso da linguagem no ciberespaço: um para construção e outro para comunicação. 0 uso da linguagem para construção relacionase com a linguagem de programação e de desenvolvimento de programas. Já a linguagem usada para comunicação diz respeito à "linguagem natural" que vem progressivamente se adaptando às novas tecnologias, inclusive considerando as limitações que essas tecnologias nos impõem, tentando, principalmente, compensar a perda da emotividade e dos elementos prosódicos e de linguagem corporal/gestual que, nas relações face a face, podem ser mais facilmente observados.

Na sequência deste artigo, discutirei o segundo tipo de uso da linguagem no ciberespaço (para comunicação), em uma Comunidade de Prática, através da análise da participação de um aluno novato em um curso a distância para coordenadores.

\section{Percurso metodológico}

Na empresa em que os dados para este estudo de caso foram coletados, uma das responsabilidades de minha função era o desenvolvimento de ações (cursos, seminários, reuniões pedagógicas) e materiais (textos, artigos, instrumentos reflexivos) para a formação continuada dos coordenadores pedagógicos da organização, uma rede de escolas de idiomas.

Essa responsabilidade permitiu a busca de inovação em ações de formação continuada. Uma dessas inovações foi o curso 
e-ducation, cujo título fazia alusão tanto à palavra educação em inglês, como à questão tecnológica, com o uso do "e-", como em e-mail, por exemplo. Ou seja, um processo de educação continuada eletrônica à distância.

Durante a aplicação do curso, observei com surpresa a desenvoltura de Jr., aluno do curso e, na época, estagiário da área pedagógica da instituição, na interação on-line com os outros alunos, um conjunto de coordenadores cuja experiência e qualificação profissional poderiam facilmente intimidar participantes novatos e menos experientes. Onde estava o agente facilitador dessa equação que permitia a Jr. interagir de forma aparentemente tão tranquila com os outros participantes? Em Jr., ou em um ou mais membros mais experientes do grupo?

Com essa inquietação em mente, constitui um recorte do corpus linguístico da pesquisa de doutorado que realizava na ocasião e organizei minha reflexão para que pudesse aprofundar a compreensão acerca da participação de Jr. no curso. Contudo, como essa inquietação não estava diretamente ligada aos objetivos de minha pesquisa, decidi tratar esse recorte como um estudo de caso a ser investigado paralelamente ao trabalho de doutorado.

A opção pelo estudo de caso se deu em virtude da abertura que essa caracterização de pesquisa oferece aos pesquisadores. Segundo Nunan (1992), estudos de caso são híbridos já que, em geral, se utilizam de um variado conjunto de métodos para coleta e análise de dados, em vez de ficarem restritos a um procedimento metodológico único. Ainda segundo esse autor, da mesma forma que em pesquisas etnográficas, estudos de caso também permitem a utilização de procedimentos qualitativos de pesquisa aliados à utilização de dados quantitativos e até estatísticos.

A tipologia de Stenhouse (1983) acerca dos estudos de caso também acolheu essa minha reflexão. Segundo o autor, entre os tipos de estudo de caso, há aqueles em que o professor é o pesquisador. Esses estudos incluem pesquisas de sala de aula, ou de ambientes de aprendizagem conduzidos por professores, que usam suas posições de participantes como base para a observação e análise de uma dada situação.

Outra característica dos estudos de caso é a possibilidade que oferecem de enfocar recortes de processos longitudinais e situados de pesquisa, como é o caso desta investigação. 


\subsection{Contexto do estudo e participantes}

Tendo o objetivo de que o e-ducation se constituísse em um curso de longa duração, previ em seu desenho inicial que o mesmo ocorresse em módulos com duração aproximada de quatro meses. Dessa forma, a cada módulo poderia tratar de temas diferentes e implementar alterações que aproximassem cada vez mais o curso das necessidades e interesses dos seus participantes. Assim, o primeiro módulo tratou de estratégias de aprendizagem, o segundo discutiu o senso comum pedagógico, e o terceiro, aspectos teóricos e práticos da reflexão de professores.

Nesse sentido, de acordo com as definições de Comunidade de Prática de Lave e Wenger (1991), Wenger (1998) e Gordin e colaboradores (1996), mencionadas anteriormente neste texto, considero o curso e-ducation uma instância de Comunidade de Aprendizagem de base profissional ou, em outras palavras, uma Comunidade de Prática em que os participantes, inseridos em um contexto de trabalho, puderam se aprofundar em temas necessários ao seu desenvolvimento profissional.

Os alunos participantes dessa comunidade eram a princípio sete coordenadores (seis de inglês e um de espanhol), que na ocasião do estudo atuavam em uma rede de escolas de línguas e, funcionalmente, se reportavam a mim, professor do curso. Porém, no decorrer dos três módulos do curso, em função de solicitações dos alunos e de reestruturações da empresa promotora do curso, houve mudanças no grupo, o que trouxe para o conjunto original de participantes novos membros, entre eles Jr., cuja participação é foco deste estudo.

Todos os participantes do curso tinham ciência e concordaram com a utilização de suas interações no estudo. Além disso, tiveram a oportunidade de conhecer minhas interpretações acerca do processo, até como forma de aprendizagem sobre um tipo possível de pesquisa de ser feita a partir de um curso on-line.

Para começar a constituir as interpretações acerca da participação de Jr. no curso, relacionarei, no quadro a seguir, os demais participantes, os módulos do curso nos quais participaram, suas idades e seu tempo de experiência como coordenadores'.

1. Tendo em mente que neste trabalho estudarei, mais especificamente, a participação de Jr. em algumas tarefas do curso, me preocupei em fornecer mais informações sobre ele, se comparado ao restante do grupo. 
Quadro 1 - Participantes

\begin{tabular}{|c|c|c|c|}
\hline Participantes ${ }^{2}$ & $\begin{array}{l}\text { Módulos } \\
\text { cursados }\end{array}$ & $\begin{array}{l}\text { Idade } \\
\text { (anos) }\end{array}$ & $\begin{array}{l}\text { Tempo de experiência como coor- } \\
\text { denador }\end{array}$ \\
\hline Chi & 1,2 e 3 & 46 & 15 anos \\
\hline $\mathrm{Ce}$ & 1,2 e 3 & 50 & 20 anos \\
\hline $\mathrm{Ma}$ & 1,2 e 3 & 36 & 10 anos \\
\hline Ghe & 1,2 e 3 & 52 & 20 anos \\
\hline $\mathrm{Fe}$ & 1,2 e 3 & 48 & 15 anos \\
\hline Dan & 2 e 3 & 38 & 06 anos \\
\hline Emi & 3 & 34 & 10 anos \\
\hline $\mathrm{Gi}$ & 3 & 52 & 25 anos \\
\hline Marcos & professor & 37 & 12 anos \\
\hline Jr. & 3 & 21 & $\begin{array}{l}\text { Cursava Letras na Universidade de São } \\
\text { Paulo. Ex-estagiário recém-efetivado na } \\
\text { organização, cuidava da parte pedagógica } \\
\text { do site da organização. Não tinha sob sua } \\
\text { responsabilidade coordenação de pessoas. }\end{array}$ \\
\hline
\end{tabular}

Para que se tenha uma ideia mais clara acerca do processo em questão, ressalto que para este trabalho foi analisada a participação de Jr. em uma das atividades (Learning Chain) do curso. Essa atividade é desenvolvida depois de todos os participantes terem lido textos relacionados ao tópico em estudo (selecionados pelo professor) e respondido questões reflexivas sobre os mesmos.

A Learning Chain se dá por meio da troca de e-mails entre os participantes, e seu objetivo é permitir que eles interajam e compartilhem experiências pessoais e impressões relacionadas aos temas discutidos a partir das leituras. 0 nome da atividade Learning Chain foi escolhido por acreditar na possibilidade de aprendizagem a partir e através do ato de compartilhar experiências pessoais. A palavra chain (corrente, em inglês) relaciona-se à dinâmica do envio das mensagens. Isto é, um 2. Apelidos fictícios dos participantes participante qualquer inicia a corrente enviando uma mensagem para todos os outros com as suas impressões sobre o texto lido, buscando relacionar o conteúdo com as suas experiências 
vicárias, numa tentativa de tornar a participação deles no curso a mais significativa possível. Na sequência, outro participante (não estabelecido previamente), a partir do texto original escrito pelo primeiro aluno, faz suas intervenções e reenvia a mensagem também para todos os seus colegas, com as suas colocações, tanto em relação ao texto lido, quanto em relação ao que foi escrito pelo primeiro aluno. E, assim, a corrente segue até que todos tenham tido a oportunidade de se expressar.

0 resultado de uma Learning Chain acabada é uma longa mensagem final colorida, já que cada participante escolhe uma cor de fonte para participar, com todas as intervenções (questionamentos, elogios, concordâncias, discordâncias, brincadeiras etc.) de todos os participantes.

Nessa última mensagem da cadeia, pode-se encontrar um diálogo que foi sendo construído assincronamente como se fosse um off-line chat. $\mathrm{E}$, além disso, é uma mensagem na qual as experiências dos participantes, aos poucos, se tornam o foco e a base da interação, ganhando até mais importância que o próprio texto lido.

No módulo em questão do curso, houve três Learning Chains. Neste trabalho, analiso a participação de Jr. a partir da mensagem final de cada uma delas, como veremos a seguir.

Para essa análise, primeiramente fiz o levantamento do número de intervenções de Jr. em relação ao dos outros participantes. Em seguida, procedi à análise do conteúdo das interações a fim de identificar a função de cada uma delas nas Learning Chains para, então, finalmente, analisar a recorrência e o possível sentido dos conteúdos nas interações.

\section{Alguns dados e interpretações sobre a participação de Jr.}

Primeiramente justifico a escolha de Jr. como participante focal deste estudo por entender que, além de ser um dos três alunos novos que participaram do Módulo 3 do curso, é o mais jovem deles, sendo também o profissional com menor tempo de experiência. Assim, se o objetivo é entender a participação periférica legítima de um novato em uma Comunidade de Prática, julguei ser Jr. o participante mais representativo do termo novato. 


\subsection{A quantidade da participação}

O início da análise da participação de Jr. nas Learning Chains já possibilitou que me surpreendesse.

Quadro 2 - Número de intervenções de Jr. nas Learning Chains

\begin{tabular}{|c|c|c|}
\hline Learning Chain 1 & Learning Chain 2 & Learning Chain 3 \\
\hline $\begin{array}{c}6 \text { intervenções } \\
3^{\circ} \text { maior número de } \\
\text { intervenções entre } \\
\text { todos os participantes }\end{array}$ & $\begin{array}{c}\text { 9 intervenções } \\
\text { intervençõos entre } \\
\text { os participantes }\end{array}$ & $\begin{array}{c}11 \text { intervenções } \\
\text { 0 maior número de } \\
\text { intervenções entre } \\
\text { os participantes }\end{array}$ \\
\hline
\end{tabular}

Antes de olhar com atenção para as mensagens finais das Learning Chains, acreditava que por ser o novato no grupo, Jr. provavelmente teria tido uma participação numericamente menor, ou seja, com um número menor de comentários e com intervenções escassas na interação. No entanto, como mostrei no Quadro 2, Jr. teve, pelo menos do ponto de vista quantitativo, uma participação marcante nas Learning Chains, principalmente nas duas últimas, o que parece indicar que, nesse caso, a participação periférica legítima não teve relação direta com o número de intervenções do aluno novato se comparado ao restante do grupo. Jr. participou tanto quanto ou até mais que os outros, o que, por outro lado, poderia também mostrar uma tendência dos mais novatos tentarem marcar mais suas posições que os alunos já conhecidos.

Enfim, todas essas suposições me deixaram ainda mais curioso para entender o tipo de participação de Jr. e, com isso em mente, procedi à análise de conteúdo das interações.

Com base nas mensagens finais das três Learning Chains, foram mapeadas todas as intervenções de Jr., de forma que pudesse ter uma ideia mais clara sobre as estratégias que foram usadas para que ele, novato, pudesse interagir com os outros participantes mais antigos no grupo.

Para mapear as interações, isolei as intervenções de Jr. nas mensagens e, então, busquei interpretar a função dessas intervenções. Como resultado, após analisar as três mensagens finais da atividade Learning Chain, obtive os seguintes dados: 


\section{Quadro 3 - Funções das intervenções de Jr. nas Learning Chains}

\begin{tabular}{|c|c|c|}
\hline \multirow{6}{*}{ 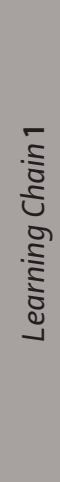 } & Função da intervenção & Ocorrências \\
\hline & $\begin{array}{l}\text { - traz referentes importantes para a argumentação (autores, livros, } \\
\text { opiniões de participantes mais antigos ou mesmo do mediador) }\end{array}$ & 05 \\
\hline & - coloca-se na posição de aprendiz & 03 \\
\hline & $\begin{array}{l}\text { - pede a aprovação dos outros para suas intervenções, implicando-os } \\
\text { por meio de perguntas abertas ao grupo }\end{array}$ & 02 \\
\hline & $\begin{array}{l}\text { - protege-se, declarando não ter certeza sobre a afirmação a fazer ou } \\
\text { relativizando o que escreve }\end{array}$ & 02 \\
\hline & - relata um caso ou experiência pessoal vivida & 01 \\
\hline
\end{tabular}

\begin{tabular}{|c|c|c|}
\hline \multirow{9}{*}{ 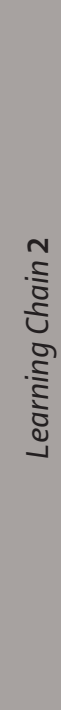 } & Função da intervenção & Ocorrências \\
\hline & - elogia outras falas & 04 \\
\hline & - coloca-se na posição de aprendiz & 03 \\
\hline & $\begin{array}{l}\text { - pede a aprovação dos outros para suas intervenções, implicando-os } \\
\text { através de perguntas abertas ao grupo }\end{array}$ & 03 \\
\hline & - explicita concordância com outros colegas & 03 \\
\hline & $\begin{array}{l}\text { - traz referentes importantes para sua argumentação (autores, livros, } \\
\text { opiniões de participantes mais antigos ou mesmo do mediador) }\end{array}$ & 01 \\
\hline & - relata um caso ou experiência pessoal vivida & 01 \\
\hline & - desvaloriza-se perante os outros participantes & 01 \\
\hline & - discorda de outros participantes & 01 \\
\hline
\end{tabular}

\begin{tabular}{|c|c|c|}
\hline \multirow{8}{*}{ 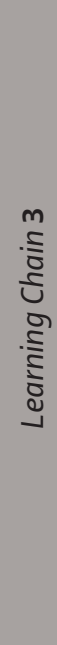 } & Função da intervenção & Ocorrências \\
\hline & - coloca-se na posição de aprendiz & 04 \\
\hline & $\begin{array}{l}\text { - protege-se, declarando não ter certeza sobre a afirmação a fazer ou } \\
\text { relativizando o que escreve }\end{array}$ & 04 \\
\hline & $\begin{array}{l}\text { - pede a aprovação dos outros para suas intervenções, implicando-os } \\
\text { através de perguntas abertas ao grupo }\end{array}$ & 03 \\
\hline & - explicita concordância com outros colegas & 03 \\
\hline & $\begin{array}{l}\text { - traz referentes importantes para sua argumentação (autores, livros, } \\
\text { opiniões de participantes mais antigos ou mesmo do mediador) }\end{array}$ & 02 \\
\hline & - desvaloriza-se perante os outros participantes & 02 \\
\hline & - discorda de outros participantes & 01 \\
\hline
\end{tabular}


Ao analisarmos o conjunto das três Learning Chains, teremos como intervenções mais recorrentes:

- coloca-se na posição de aprendiz, com dez ocorrências;

- traz referentes importantes para sua argumentação (autores, livros, opiniões de participantes mais antigos ou mesmo do mediador) e pede a aprovação dos outros para suas intervenções, implicando-os através de perguntas abertas ao grupo, cada uma com oito ocorrências; e

- protege-se, declarando não ter certeza sobre a afirmação a fazer ou relativizando o que escreve e explicita concordância com outros colegas, cada uma com seis ocorrências.

Esses dados possibilitam algumas observações. Ao "colocarse na posição de aprendiz", em duas das intervenções, Jr., com o intuito de ilustrar sua opinião, faz narrativa de histórias pessoais, sempre se colocando como a personagem da narrativa que aprende, depois de perceber ou entender algo que antes não entendia. Em outras palavras, ao narrar, Jr., conscientemente ou não, acaba trabalhando na construção de sua imagem de bom aprendiz junto ao grupo. Ainda em relação a se colocar como aprendiz, na Learning Chain 3, Jr. cheg̉a a explicitar a sua posição periférica, pedindo licença para comentar algo: "Gente, eu sei que não sou nenhum coordenador ainda, mas gostaria de...".

0 ato de compartilhar suas experiências também foi importante para que os outros participantes do grupo pudessem conhecer mais Jr., um dos fatores mencionados por Garrison, Anderson e Archer (1994) como importantes para que o elemento cognitivo de uma comunidade possa ocorrer. Nas palavras desses autores:

\footnotetext{
Altos índices de presença social, aliados a altos níveis de comprometimento e participação, são necessários para o trabalho colaborativo e para o desenvolvimento da capacidade de análise, avaliação, síntese, produção de novos conhecimentos, pensamento crítico e solução de problemas (HOTS - higher order thinking skills) (p. 94, tradução nossa).
}

Esses aspectos mencionados parecem indicar que uma das estratégias usadas por Jr. para poder participar no grupo foi a de assumir um papel de quem estava lá para aprender mesmo, sem a preocupação de querer mostrar uma experiência que não tinha, ou uma familiaridade que não existia em relação aos tópicos trabalhados. Se agregarmos esta minha interpretação ao fato de que essas intervenções de Jr. se deram em um grupo de educadores que, em geral, valorizam uma postura aberta para 
a aprendizagem, podemos entender essa forma de participação periférica de Jr. como apropriada, até por que não houve nenhum conflito de Jr. com qualquer outro integrante da comunidade.

É também curioso observar a segunda função mais recorrente nas intervenções de Jr. Ao "trazer referentes importantes para sua argumentação" (autores, livros, opiniões de participantes mais antigos ou mesmo do mediador), Jr. parece buscar no outro um suporte às suas opiniões. 0 mesmo ocorre, porém de forma um pouco diferente, quando depois de escrever algo, "pede a aprovação dos outros para suas intervenções, implicando-os através de perguntas abertas ao grupo", como em "vocês já não sentiram isso?". Esta também parece ter sido uma forma de participação periférica legítima eficaz, se levarmos em conta que em diversas dessas oportunidades Jr. obteve o apoio solicitado de vários dos participantes.

Além das formas de participação abordadas acima, Jr. também busca se proteger nas interações "modalizando o seu discurso, seja declarando não ter certeza sobre a afirmação a fazer, ou relativizando o que escreve". Ao buscar esse caminho, Jr. evita conflitos e parece conseguir um bom entrosamento com o grupo, não gerando polêmicas com suas intervenções, mesmo nas duas oportunidades nas quais discordou de opiniões dos colegas. Em uma das vezes, "imitou" uma fala anterior usada pelo mediador para discordar de alguém. Na outra, se protegeu dizendo "não sei se concordo...".

Assim, se considerarmos as poucas discordâncias de Jr. em relação às opiniões do grupo, em conjunto com o número de ocorrências nas quais ele concordou e elogiou os colegas, podemos interpretar que Jr. cuidou de si, sem se expor. Isto é, protegeu sua face, sem deixar de colocar suas opiniões sobre os textos lidos e sobre as mensagens de seus colegas, buscando construir com sua participação um ambiente favorável no qual, ao assumir um papel declaradamente de aprendiz em relação aos seus colegas, pudesse dar suas opiniões e, inclusive, discordar sem ter maiores problemas.

\section{E então?}

Depois de ter discutido alguns aspectos da aprendizagem a partir da perspectiva de diferentes tipos de comunidades, procurei através da análise das interações de Jr. em uma Comunidade 
de Prática verificar como se deu sua participação, de forma a entender se essa participação poderia ser caracterizada como periférica legítima, o que parece ter sido o caso.

Para que o estudo fosse feito e essa consideração fosse possível, no entanto, alguns aspectos precisam ser enfatizados. Um deles é a possibilidade da utilização de ferramentas tecnológicas comuns (e-mail) em processos de formação continuada. Em outras palavras, enquanto muitas vezes esperamos e procuramos por tecnologias educacionais perfeitas, podemos usar o que já temos no dia a dia e explorá-las de forma a propiciar a reflexão e a aprendizagem.

Para isso, no entanto, não basta a simples proposição de trocas de mensagens. Acredito que um dos fatores de sucesso das trocas de e-mail do e-ducation foi a sua organização enquanto curso, isto é, as interações do e-ducation foram metodologicamente pensadas e organizadas com base em objetivos definidos que puderam ser explicitados e avaliados ao longo e ao final dos módulos.

Além disso, a existência de um contexto profissional aberto à aprendizagem, e a disposição do grupo para participar do curso e compartilhar suas experiências pessoais, sabendo que essas experiências passariam a constituir as experiências dos outros participantes, foram essenciais para a relevância das trocas ocorridas e para o decorrente aprendizado profissional dos participantes.

É importante também destacar os benefícios que o estudo de caso pode trazer para os educadores. Com o estudo de caso, tanto os pesquisadores quanto os participantes podem ter acesso à materialização da reflexão, ou seja, podem concretizar os ganhos e a aprendizagem que a postura investigativa pode proporcionar.

Neste caso, especificamente, foi muito gratificante aprender, através e com Jr., que a postura explicitamente declarada de aprendiz parece se constituir em uma forma de participação periférica legítima eficaz para Comunidades de Prática.

Se exercido, esse aprendizado pode ajudar a enfraquecer posturas mais fechadas e resistentes de alguns grupos nos quais, muitas vezes, há mais preocupação em se ensinar as mesmas coisas do que em aprender coisas novas.

Essa postura é orientada para a aprendizagem e demanda dos participantes um investimento nas relações, como defendem 
Wenger, McDermott e Snyder (2002):

A estrutura denominada comunidade é crítica para a existência de uma efetiva rede interligada de conhecimento. Uma Comunidade de Prática é constituída por um grupo de pessoas que interagem, aprendem em conjunto, constroem relações e, em um processo, desenvolvem o senso de pertencimento e de comprometimento mútuo (p. 34, tradução nossa).

Assim, encerro este artigo com a percepção de que uma boa estratégia para nos iniciarmos em uma Comunidade de Prática e aprender, mesmo com uma participação periférica, ou seja, não integral, é assumir uma atitude declarada de aprendiz, cultivar as relações e co-laborar na e com a comunidade, fortalecendo-a em sua característica principal: a aprendizagem.

\section{REFERÊNCIAS}

CICOGNANI, A. On the Linguistic Nature of Cyberspace and Virtual Communities. Virtual Reality, v. 3, p. 16-24, SpringerVerlag London Ltd, 1998.

DOWNES, S. Learning in Communities. Disponível em: <http://www.learnscope.anta.gov.au/learnscope/print.asp>. Acesso em: mar. 2010.

GARRISON, D. R.; ANDERSON, T.; ARCHER, W. Critical Inquiry in a Text-Based Environment: Computer Conferencing in Higher Education. The Internet and Higher Education, v. 2 (2-3), p. 87-105. Disponível em: <http://sciserv.ub.uni-bielefeld.de/ elsevier/10967516/>. Acesso em: mar. 2010.

GORDIN, D.N. et.al. Using the World Wide Web to build learning communities in K-12. Journal of Computer-Mediated Communication, v. 2, n. 3, dez. 1996.

JONASSEN, D.H.; PECK, K.L.; WILSON, B.G. Learning with Technology: A Constructivist Perspective. Merrill/Prentice Hall, 1999.

LAVE, J.; WENGER, E. Situated Learning: Legitimate Peripheral Participation. Cambridge University Press, 1991. 
NUNAN, D. Research Methods in Language Learning. Cambridge: University Press, 1992.

RHEINGOLD, H. A Slice of My Virtual Community. In: HARASIM, L.M. Global Networks: Computers and International

Communication. Massachusetts: The MIT Press, 1993.

STENHOUSE, L. Case Study in Educational Research and Evaluation. In: BARTLETT, L., KEMMIS, S.; GUILLARD, G. (eds.). Case Study: an overview. Melbourne: Deaking University Press, 1983.

TÖNNIES, F. Community and Society (traduzido por LOOMIS, C.). East Lansing: Michigan State University Press, 1957.

VYGOTSKY, L.S. (1934). A formação social da mente. São Paulo: Martins Fontes, 1984.

WENGER, E. Communities of Practice: Learning, meaning and identity. Cambridge: University Press, 1998.

WENGER, E.; MCDERMOTT, R.; SNYDER, W.M. Cultivating Communities of Practice: A guide to managing knowledge. Harvard: Harvard Business School Press, 2002.

Recebido em: 04/12/2013

Revisto em: 16/04/2014

Aprovado em: 17/04/2014 